\title{
An Analysis of Purchasing Power Parity for the Turkish Economy Using Unit Root Testing with Multiple Structural Breaks
}

\author{
BETÜL GÜR * \\ * İstanbul Ticaret Üniversitesi \\ E-mail: bgur@ticaret.edu.tr
}

Copyright (C) 2015 BETÜL GÜR. This is an open access article distributed under the Eurasian Academy of Sciences License, which permits unrestricted use, distribution, and reproduction in any medium, provided the original work is properly cited.

\begin{abstract}
The application of the law of one price to the international market is purchasing power parity. Purchasing power parity associates the prices of all goods used in foreign trade with the exchange rate. If the purchasing power parity is valid, the changes in the nominal exchange rates balance the changes at the price levels among countries. Thus, the real exchange rate fluctuates about a fixed average. For this, the testing of the purchasing power parity can be done through studying the unit root properties of the real exchange rate. In this study, the real exchange rate for Turkey has been examined using unit root tests with standard and multiple breaks. It has been determined that purchasing power parity is not valid in the Turkish economy.
\end{abstract}

Keywords: Purchasing Power Parity, Real Exchange Rate, Structural Break Unit Root Tests, The Law of One Price, International Trade

JEL: C22, F30, F31

\section{Çoklu Kırılmalı Birim Kök Yardımıyla Satın Alma Gücü Paritesinin Türkiye İçin Analizi}

\section{ÖZET}

Tek fiyat kanunun uluslararası piyasaya uygulanması satın alma güicü paritesi olarak adlandırılır. Satın alma gücü paritesi, dış ticarete konu olan bütün malların fiyatlarını döviz kuru ile ilişkilendirir. Eğer satın alma gücü paritesi geçerli ise, ülkeler arasındaki fiyat düzeyinde meydana gelen değişimler, nominal döviz kurunda meydana gelecek değişimler tarafindan dengelenecektir. Böylece reel döviz kuru sabit bir ortalama etrafında dalgalanacaktır. Bunun için, satın alma gücü paritesinin test edilmesi reel döviz kurunun birim kök özelliklerinin incelenmesi ile yapılabilir. Çalışmada, Türkiye için reel döviz kuru serisi standart ve çoklu kırılmalı birim kök testleri ile sınanmış ve satın alma gücü paritesinin Türkiye ekonomisi için geçerli olmadığı belirlenmiştir.

Anahtar Kelimeler: Satın Alma Gücü Paritesi, Reel Döviz Kuru, Yapısal Kırılmalı Birim Kök Testleri, Tek Fiyat Kanunu, Uluslararası Ticaret 


\section{GİRIŞ}

Satınalma gücü paritesi (SGP), parasal modellerin önemli bir unsurudur. Değişken fiyat parasal model SGP'nin her zaman gerçekleştiğini varsayarken, döviz kuru dinamiği modeli bunu uzun dönemli bir olgu olarak almaktadır. SGP'nin geçerliliği için zorunlu fakat yeterli olmayan şart, tek fiyat kanununun geçerliliğidir. Ancak kısa dönemde, daha homojen olan birincil ürün piyasalarında dahi tek fiyat kanununun geçerliliği tartışmalıdır. Tek fiyat kanunu geçerli olsa bile bu SGP'si için yeterli değildir. Çünkü SGP toplam fiyat indekslerine göre oluşturulmaktadır. Bu nedenle, tüketici tercihlerindeki farklılıklar, sektörler arasında nispi verimlilik farklılıkları ve ticarete konu olan ve olmayan mallar arasında nispi fiyat farklılıkları, tarifeler, taşıma maliyetleri, farklı ülkelerdeki farklı fiyatlar genel düzeyleri tek fiyat kanunu geçerli olsa dahi, SGP'nin geçersiz olabileceğini ortaya koymaktadır (Enders, 1989: 59).

SGP yaklaşımı sabit ya da en azından ortalama değerine dönme eğiliminde olan ve stokastik trend içermeyen bir reel kur düzeyini gerektirmektedir. Denge SGP'ye doğru reel döviz kuru uyarlamalarının bilinmesi, uluslararası makroekonomik sistemin ne ölçüde dengesizlikleri giderici olduğunun belirlenmesinde de önemli bir rol oynamaktadır. SGP'nin uzun dönemde geçerli olabilmesi için reel döviz kuru durağan olmalı yani birim kök içermemelidir. Eğer reel kur durağan değilse kurdaki sapmalar kalıcı olacak ve nominal kur fiyat farklılıklarını giderecek şekilde hareket etmediği için SGP geçerli olmayacaktır (Bozoklu ve Yılancı, 2010: 592).

Dolayısıyla satın alma gücü paritesi sınanırken genelde reel döviz kuru serisinin durağan olup olmadığı araştırılmalıdır. Eğer reel döviz kuru durağan yani sabit bir ortalamaya dönüyor ise, SGP geçerlidir yani ülkelerarasında fiyat düzeyinde meydana gelecek herhangi bir değişim nominal döviz kurunda ona denk gelecek bir değer kaybı veya kazanımı ile dengelenecektir. Eğer reel döviz kuru durağan değil ise SGP geçerli değildir.

Geleneksel birim kök testlerinin zaman serilerinde olası yapısal değişimleri dikkate almaması, bu tür değişimlerin varlığında bu testlerin gücünü azaltmaktadır. Bu çalışmada, Türkiye'de 2000 y1lı ve sonrasındaki ekonomik gelişmeleri göz önüne alınarak 2000:01-2014:12 dönemi için SGP'nin geçerliliği yapısal kırılmaları dikkate almayan ADF ve PP testlerinin yanı sıra çoklu yapısal kırılmalı birim kök testleri de incelenmiştir. Yapısal kırılmaları dikkate alan ve almayan testlerin ortak sonucu olarak Türkiye için geçersiz olduğu belirlenmiştir.

\section{SATIN ALMA GÜCÜ PARITESİ}

SGP teorisi, ülkeler arasında ulusal paraların değerini tayin etmeye yönelik en eski yaklaşımdır. Bu yaklaşım hakkında ilk düşünceler 16. yüzyılda İspanya'daki Salaman Ekolü ve 17. yüzyılda İngiltere'de Jerar De Malince'in çalışmalarında yer almıştır. Ancak 20. yüzyılın başlarında İsveçli iktisatçısı Gustav Cassel bu yaklaşımın ana çatısını oluşturarak SGP teorisini matematiksel formda ifade etmiştir (Ganiev ve Emsen, 2008).

SGP teorisinde hangi kur sistemi uygulanırsa uygulansın, sonuç itibarıyla ülke paralarının alacağı değer, bu mekanizmanın işlerliği ile tesis edilmiş olacaktır. Mal hareketliliği esasına 
göre işleyen sistemde, döviz kuru sistemi sabit kur rejimi olarak tesis edilmiş olsa bile, ülkeler arasındaki fiyat farklılıklarının yaratacağı baskılar, sonuç itibarılla döviz kurunu sabit tutan ülkelerde devalüasyonu kaçınılmaz hale getirerek, mal fiyatlarının döviz cinsinden farklılığının giderilmesine yol açacaktır. Diğer taraftan döviz kurlarının piyasalarda serbestçe belirlenmesi durumunda ise kurların alacağı değer, ülkeler arasındaki göreceli fiyat değişim oranlarının bir ölçüsü olacaktır. Dolayısıyla SGP teorisinin altında yatan mantık, bir ülkedeki ulusal paranın satın alma gücünün diğer ülkelerde de aynı olması gerektiğine vurgu yapar. Yani, denge döviz kuru ülkeler arasında fiyat düzeylerinin oranı ile doğrusal bir ilişkiye sahiptir. Bu mekanizma, genel olarak uluslararası arbitraj yoluyla geçerli olur. Uluslararası ticarette arbitraj mekanizmasının işlemesi ise tek fiyat kanununun geçerliliğine zemin hazırlar. Tek fiyat kanunu da arbitraj mekanizması yoluyla uluslararası ticarete konu olan malların fiyatının her yerde aynı olması sonucunu doğurur. Fakat SGP mantığını tek fiyat kanunundan ayırt eden özelliği, tek fiyat kanunu ülkeler arasında sadece bir malın fiyatındaki eşitleme olgusunu açıklarken SGP tüm piyasaları kapsar niteliktedir. Bu doğrultuda SGP, ülkeler arasında dış ticarete konu olan mallar ile döviz kurları arasında ilişki kurmaktadır (Ganiev ve Emsen, 2008).

Merkez bankaları günümüzde parayı baskı altına alan ve paranın dış etkilere göre dalgalanmasını engelleyen sabit ve baskıcı kur rejimini terk etmiştir. Günümüzde merkez bankaları dalgalı kur rejimini kullanmaktadır. Dalgalı döviz kurunun yapısı gereği yerel para birimi bazı ülke paralarına karşı değerlenip bazı ülke paralarına göre değer kaybetmektedir. $\mathrm{Bu}$ durumda etkin bir parite hesabı için o ülkeyle ticari ve mali ilişkileriyle doğru orantılı olarak yabancı paralar dikkate alınır. Bu tarz bir hesaplama yaparak buluna kur ise 'etkin döviz kuru' olarak adlandırılmaktadır. Esnek döviz kuru sistemlerinde teorik olarak uzun dönemde satın alma gücü paritesi yaklaşımının geçerli olması gerekmektedir. Reel döviz kurları SGP teorisine uygun hareket ederlerse nominal döviz kurlarındaki değişmeler uluslararası rekabet gücünü etkilemez (Yıldırım, 2003: 21). Satın alma gücü paritesi 2 ana başlık altında incelenmektedir.

\section{Mutlak Satın Alma Gücü Paritesi}

Mutlak satın alma gücü paritesine göre döviz kurlarına dönüştürülmüş fiyat düzeylerinin ülkeler arasında aynı olmasını gerektirir. Yani belli bir mal sepetinin bir ülkedeki fiyatının, cari döviz kurlarına göre ifade edildiğinde dünyanın her yerinde aynı olacağı anlamına gelir. Bu tarz bir para birimi her ülkede eşit alım gücüne sahiptir (Yıldırm, 2003).

$\mathbf{P}_{\mathbf{d}}=\mathbf{S} \times \mathbf{P}_{\mathbf{f}}$

$\mathbf{S}:$ Anında teslim kurunu,

$\mathbf{P}_{\mathbf{d}}$ : Yurtiçi fiyat endeksini,

$\mathbf{P}_{\mathbf{f}}$ : Yurt dişı fiyat endeksini gösterir.

$\mathrm{Bu}$ eşitlikte kısaca $\mathrm{A}$ ülkesindeki para birimini $\mathrm{B}$ ülkesinin para birimine çevrildiğinde $\mathrm{B}$ ülkesinde ne kadar mal veya hizmet alınabileceği ifade edilmektedir. Bu yüzden SGP her para biriminin kendi ülkesindeki satın alma gücüyle eşit olduğu varsayımı altında kabul edilir. Yurt 
içi fiyatlar ile yurt dışı fiyatlar arasındaki fark ne kadar büyük olursa, döviz kuru da o derece yüksek olacaktır (Krugman ve Obstfeld, 2006: 371).

\section{Nispi Satın Alma Gücü Paritesi}

Göreceli SGP yaklaşımı, herhangi bir dönemde iki ülkenin para birimi arasındaki kurda meydana gelen yüzde değişimin iki ülkenin ulusal fiyat seviyeleri arasındaki değişim yüzdesine eşit olacağını ifade etmektedir. SGP teorisi yurt içindeki ve diğer ülkelerdeki enflasyon farkından yararlanmaktadır. Nispi satın alma gücü paritesinde belirlenen bir tarihteki döviz kuru değildir. Bir temel yılı belirlenerek kurların hareket yönleri izlenir. Yüksek enflasyon yaşanan bir ülkeyle düşük enflasyon yaşanan bir diğer ülke arasındaki döviz kuru iki ülkedeki enflasyon farkı derecesinde yükselir. Formülü şöyledir:

$\mathbf{S}_{1}-\mathbf{S}_{\mathbf{0}} / \mathbf{S}_{\mathbf{0}}=\mathbf{P}_{\mathrm{d}}-\mathbf{P}_{\mathrm{f}}$

$\mathbf{S}_{1}$ : Baz alınan y1lın döviz kurunu,

$\mathbf{S}_{\mathbf{1}}-\mathbf{S}_{\mathbf{0}} / \mathbf{S}_{\mathbf{0}}$ : Kurdaki yüzde değişmeyi,

$\mathbf{P}_{\mathbf{d}}$ : İki dönem arasında ele alınan ülkedeki enflasyon oranını,

$\mathbf{P}_{\mathbf{f}}$ : Yabancı ülkedeki enflasyon oranını ifade etmektedir.

$\mathrm{Bu}$ formüle göre iki ülke arasındaki döviz kuru iki ülke arasındaki fiyat farklarından kaynaklanmamaktadır. Nispi satın alma gücü paritesinde döviz kurundaki değişmeler esas alınmaktadır. Dolayısıyla nispi satın alma gücü paritesi enflasyonla ilgilidir (Sarno ve Valente, 2006: 3150). Nispi satın alma gücü paritesine göre enflasyonun yüksek olduğu ülkede döviz kuruda yükselmelidir. Enflasyonla orantılı olarak döviz kuru da artmazsa o ülke mal ve hizmet ihracatında sıkıntı çekecektir. Bu durum o ülke açısından dezavantaj yaratacak ve o ülke diğer ülkelerle rekabette sıkıntı çekecektir. Tam tersi olan ithalatta ise ülkeye diğer ülkelerin malları deyim yerindeyse istila edecek ve o ülke yine rekabet edemeyecek ve yenik düşecektir. Sonuçta o ülke dış ticarette açıklar verecek ve bu açıklar giderek daha da artacaktır.

Nispi satın alma gücü paritesi uzun vadede ve kısa vadede olmak üzere iki farklı süreçte izlenmektedir. Her analizde olduğu gibi bu analizde de verilerin fazla olması sonucun daha güvenilir olmasını sağlayacaktır. Yine her zaman serisi analizinde olduğu gibi bu analizde de zaman aralıklarıyla oynamamak gerekmektedir. Literatürde bugüne kadar yapılan araştırmalar nispi satın alma gücü paritesinin kısa vadede daha geçerli olduğunu göstermektedir. Kısa vadede geçerli olmasının ana sebebi iktisattaki zaman kavramına uygun olarak kısa vadede bazı değişkenlerin sabit olmasıdır.

\section{LITERATÜR}

Tablo 1'de görüldüğü gibi, literatürde satın alma gücü paritesinin geçerliliğini araştıran çalışmalar geniş bir tartışma alanı bulmuştur. Yapılan çalışmalar incelendiğinde, ülkelerin tek tek ya da birlikte ele alındığı ve farklı zaman serileri yöntemlerinin kullanıldığ görülmektedir. 
An Analysis of Purchasing Power Parity for the Turkish Economy Using Unit Root Testing with Multiple Structural Breaks

\begin{tabular}{|c|c|c|c|c|c|}
\hline Araştırmacılar & Örneklem & Dönem & Frekans & Yöntem & Sonuç \\
\hline Coakley ve Fuertes (1997) & G10 ve İsviçre & 1973:07-1996:06 & Aylik & Panel Birim Kök & SGP Geçerli \\
\hline \begin{tabular}{|l} 
O'Connell (1998) \\
\end{tabular} & 64 Ülke & 1973:02-1995:04 & Çeyreklik & Panel Birim Kök & SGP Geçersiz \\
\hline Telatar ve Kazdağlı (1998) & Türkiye & 1980:10-1993:10 & Aylik & Eşbütünleşme & SGP Geçersiz \\
\hline Sarno (2000) & Türkiye & 1980:01-1997:12 & Aylik & ESTAR & SGP Geçerli \\
\hline Erlat (2003) & Türkiye & 1984:01-2000:09 & Aylik & $\begin{array}{l}\text { Kırılmalı Birim Kök } \\
\text { ve ARFIMA model }\end{array}$ & SGP Geçerli \\
\hline Yazgan (2003) & Türkiye & 1982:01-2001:04 & Çeyreklik & Eşbütünlemie & SGP Geçerli \\
\hline $\begin{array}{l}\text { Breitung ve Candelon } \\
(2005)\end{array}$ & 10 Ülke & 1981:01-2001:08 & Aylik & $\begin{array}{c}\text { Kırılmalı Panel Birim } \\
\text { Kök }\end{array}$ & $\begin{array}{l}\text { SGP } 5 \text { Ülke İçin } \\
\text { Geçerli ve } 5 \text { Ülke } \\
\text { İçin Geçersiz. }\end{array}$ \\
\hline Alba ve Park (2005) & Türkiye & 1973:01-2002:07 & Aylik & TAR & SGP Geçerli \\
\hline Cerrato ve Sarantis (2007) & 20 OECD Ülkesi & $\begin{array}{l}\text { 1973:01-2000:01 } \\
\text { 1981:01-1999:10 }\end{array}$ & Aylik & Panel Birim Kök & SGP Geçersiz \\
\hline $\begin{array}{l}\text { Kalyoncu ve Kalyoncu } \\
(2008)\end{array}$ & 25 OECD Ülkesi & 1980:01-2005:04 & Çeyreklik & Panel Birim Kök & SGP Geçerli \\
\hline Çağlayan ve Sak (2009) & 26 OECD Ülkesi & 1996:01-2006:04 & Aylik & $\begin{array}{c}\text { Panel Birim Kök ve } \\
\text { Pedroni Panel } \\
\text { Eşbütünleşme }\end{array}$ & SGP Geçersiz \\
\hline 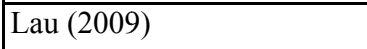 & 4 OECD Ülkesi & $1950-1995$ & Y1ll1k & Panel Birim Kök & SGP Geçerli \\
\hline $\begin{array}{l}\text { Kalyoncu, Kula ve Aslan } \\
(2010)\end{array}$ & 13 MENA Ülkesi & 1970-1998 & Yillik & Kırılmalı Birim Kök & SGP Geçerli \\
\hline Güloğlu ve diğerleri (2011) & 18 Ülke & 1991:01-2008:03 & Ayl1k & $\begin{array}{c}\text { Kırılmalı Panel Birim } \\
\text { Kök }\end{array}$ & SGP Geçerli \\
\hline Holmes ve diğerleri (2012) & 26 OECD Ülkesi & 1972:01-2008:02 & Çeyreklik & $\begin{array}{c}\text { Kırılmalı Panel Birim } \\
\text { Kök }\end{array}$ & SGP Geçerli \\
\hline Güney ve diğerleri (2012) & $\begin{array}{c}9 \text { GOÜ ve Afrika } \\
\text { Ülkeleri }\end{array}$ & $\begin{array}{l}\text { 1995:01-2010:02 } \\
\text { 1994:12-2009:05 }\end{array}$ & Aylik & $\begin{array}{c}\text { Lineer, Lineier } \\
\text { Olmayan ve Kırılmalı } \\
\text { Birim Kök }\end{array}$ & SGP Geçerli \\
\hline Y1ldırım ve Yildırım (2012) & Türkiye & 1990:01-2009:12 & Aylik & Kırılmalı Birim Kök & SGP Geçerli \\
\hline Yıldırım ve diğerleri (2013) & $\begin{array}{c}\text { Türkiye, AB-15, } \\
\text { G-8, OECD } \\
\text { Ülkeleri }\end{array}$ & $\begin{array}{l}1975-2012 \\
1980-2012\end{array}$ & Y1llik & Panel Birim kök & SGP Geçerli \\
\hline Ceylan ve Ulucan (2014) & OECD Ülkeleri & $1970-2013$ & Y1ll1k & $\begin{array}{l}\text { KSS ve AESTAR } \\
\text { Testleri }\end{array}$ & $\begin{array}{c}5 \text { Ülkede } \\
\text { Geçersiz, } 20 \\
\text { Ülkede SGP } \\
\text { Geçerli }\end{array}$ \\
\hline Tıraşoğlu (2014) & OECD Ülkeleri & 1993:Q1-2011.Q1 & Çeyreklik & $\begin{array}{l}\text { Yapısal Kırılmalı } \\
\text { Birim Kök }\end{array}$ & SGP Geçersiz \\
\hline
\end{tabular}

Tablo-1: SGP Geçerliliği için Literatürde Yer alan Bazı Çalışmalar

\section{EKONOMETRIK BULGULAR}

Ekonometri literatüründe satın alma gücü paritesi hipotezinin mutlak versiyonu, reel döviz kurunun trend durağan olmasını veya reel döviz kurunun bileşenlerinin (nominal döviz kuru ve nispi fiyatlar) eşit bir biçimde eşbütünleşik olması gerektiğini ifade etmektedir (Güloğlu ve diğerleri, 2011: 1). SGP'nin geçerliliğinin saptanmasında en çok kabul gören reel döviz kurlarının durağanlığın sınanması yaklaşımı olup, durağanlığın araştırılmasında kullanılan 
birim kök testlerinde dikkat edilmesi gereken birkaç nokta bulunmaktadır. Bunlardan ilki, birim kökün test edildiği regresyona sabit ve/veya trendin dahil edilmesinin seri özelliklerine uygun olarak yapılmasıdır. İkincisi ise, serilerdeki muhtemel yapısal kırılmaların göz önüne alınmasidir.

SGP'nin geçerli olması durumunda, reel döviz kuru durağan olmalıdır, yani nispi fiyatlardaki değişiklikler nominal döviz kurundaki değişimler ile dengelenmeli, reel döviz kuru belli bir ortalama etrafında dalgalanmalı ve uzun dönem denge değerine yaklaşmalıdır. Reel döviz kurunda birim kök olması, reel döviz kuruna gelen şokların kalıcı olduğunu ve söz konusu ülke için SGP teorisinin geçerli olmadığını ifade etmektedir (Tıraşoğlu, 2014).

Satın alma gücü paritesinin geçerliliği, reel döviz kuru serisinin (RDK, 2005=100) durağanlığının incelenmesiyle test edilmiş ve logaritmik formda ele alınarak analiz edilmiştir. Çalışma periyodu aylık veri biçiminde 2000:01-2014:12 dönemini kapsamaktadır. Analiz iki aşamada gerçekleştirilmiştir. Birinci aşamada yapısal kırılmaları dikkate almayan genişletilmiş Dickey Fuller (Augmented Dickey Fuller: ADF) (1979) ve Phillip-Perron (PP) (1989) birim kök testleri ile incelenmiştir.

\begin{tabular}{|l|c|c|c|c|}
\hline \multirow{2}{*}{ Değişkenler } & \multicolumn{2}{|c|}{ ADF Testi } & \multicolumn{2}{c|}{ PP Testi } \\
\cline { 2 - 5 } & Düzey & Birinci Mertebe Farkı & Düzey & Birinci Mertebe Farkı \\
\hline LnRDK & -1.216 & $-7.453^{*}$ & -1.077 & $-7.426^{*}$ \\
\hline Anlamlılık Düzeyi & \multicolumn{4}{|c|}{ Kritik Değerler } \\
\hline$\% 1$ & -3.523 & -3.542 & -3.738 & -3.692 \\
\hline$\% 5$ & -2.976 & -2.879 & -2.813 & -2.937 \\
\hline$\% 10$ & -2.721 & -2.626 & -2.824 & -2.691 \\
\hline
\end{tabular}

*\%1, \%5 ve \%10 için anlamlı, durağan seri

Tablo-2: ADF ve PP Birim Kök Testleri Sonuçları

Birim kök sonuçlarına göre RDK serisi düzeyde durağan değildir, birinci mertebe fark alındığında durağan olmaktadır. Tablo 2' de yer verilen ve yapısal kırılmaları dikkate almayan ADF ve PP birim kök testi sonuçlarına göre Türkiye örneğinde satın alma gücü paritesi geçerli değildir.

\section{Carrion-I-Silvestre ve diğerleri (2009) Yapısal Kırılmalı Birim Kök Testi}

Carrion-i-Silvestre vd. (2009) testinde, beş tane yapısal kırılmaya izin verilmekte ve kırılma tarihleri de içsel olarak belirlenmektedir. Bu test, yapısal kırılma noktalarını Bai ve Perron (2003) algoritmasını kullanarak quasi-GLS yöntemi yardımıyla dinamik programlama süreciyle ve hata kareler toplamını minimize ederek elde etmektedï. Bu test, küçük örneklemlerde de kullanılabilme özelliğine sahiptir ve kullanılan stokastik veri üretme süreci şöyledir: 
$y_{t}=d_{t}+u_{t}$

$u_{t}=\alpha u_{t-1}+v_{t} t=0,1,2, \ldots, T$

Carron-i-Silvestre vd. (2009), bu süreçle elde edilen serilerin durağanlığını test edebilmek için beş farklı test istatistiği geliştirmiştir:

$$
\begin{aligned}
& P_{T}\left(\lambda^{0}\right)=\frac{\left[S\left(\bar{\alpha}, \lambda^{0}\right)-\bar{\alpha} S\left(1, \lambda^{0}\right)\right]}{S^{2}\left(\lambda^{0}\right)} \\
& M_{T}\left(\lambda^{0}\right)=\frac{\left[c^{-2} T^{-2} \sum_{t=1}^{T} \tilde{y}_{t-1}^{2}+(1-\bar{c}) T^{-1} \tilde{y}_{T}^{2}\right]}{s^{2}\left(\lambda^{0}\right)^{2}} \\
& \operatorname{MZ}_{\alpha}\left(\lambda^{0}\right)=\left(T^{-1} \tilde{y}_{T}^{2}-s\left(\lambda^{0}\right)^{2}\right)\left(2 T^{-2} \sum_{t=1}^{T} \tilde{y}_{t-1}^{2}\right)^{-1} \\
& \operatorname{MSB}_{\alpha}\left(\lambda^{0}\right)=\left(s\left(\lambda^{0}\right)^{-2} T^{-2} \sum_{t=1}^{T} \tilde{y}_{t-1}^{2}\right)^{1 / 2} \\
& M Z_{t}\left(\lambda^{0}\right)=\left(T^{-1} \tilde{y}_{T}^{2}-s\left(\lambda^{0}\right)^{2}\right)\left(4 s\left(\lambda^{0}\right)^{2} T^{-2} \sum_{t=1}^{T} \tilde{y}_{t-1}^{2}\right)^{1 / 2}
\end{aligned}
$$

Testin hipotezleri:

$\mathrm{H}_{0}$ : Yapısal kırılmalar altında birim kök vardır.

$\mathrm{H}_{1}$ : Yapısal kırılmalar altında birim kök yoktur.

$\mathrm{Bu}$ hipotezleri test etmek için gerekli olan asimtotik kritik değerler, bootstrapla

\begin{tabular}{|c|c|c|c|c|c|c|}
\hline \multirow{2}{*}{ Değişken } & \multicolumn{5}{|c|}{ Düzey Değerleri } & \multirow{2}{*}{ Kırılma Tarihleri } \\
\hline & $\mathbf{P}_{\mathrm{T}}$ & $\mathbf{M P}_{\mathbf{T}}$ & $\mathbf{M Z}_{\boldsymbol{a}}$ & MSB & $\mathbf{M Z}_{\mathbf{T}}$ & \\
\hline LnRDK & 23.45 & 18.29 & -22.98 & 0.12 & -2.62 & $\begin{array}{l}\text { 2001:12, 2003:04, 2005:05, } \\
\text { 2008:04, 2009:03 }\end{array}$ \\
\hline$\Delta \operatorname{LnRDK}$ & $3.64 *$ & $5.89 *$ & $-12.31 *$ & $0.14 *$ & $-5.26^{*}$ & $\begin{array}{l}\text { 2002:09, 2004:04, 2005:09, } \\
\text { 2008:07, 2009:02 }\end{array}$ \\
\hline
\end{tabular}
üretilebilmektedir. Hesaplanan test istatistiği, kritik değerden küçük olduğunda $\mathrm{H}_{0}$ hipotezi reddedilmekte ve seride yapısal kırılmaların varlığı durumunda birim kökün olmadığı, yani serinin durağan olduğu sonucuna ulaşılmaktadır. Carrion-i-Silvestre vd. (2009) testinden elde edilen sonuçlar ve kritik değerler Tablo 3 'de verilmiştir.

*\%5 anlamlılık düzeyinde durağanlığı ifade etmektedir (Bootstrap yöntemi kullanılarak 1000 yineleme ile üretilmiş kritik değerler ile karşılaştırma yapılmıştır)

Tablo-3: Carrion-i-Silvestre (2009) Çoklu Yapısal Kırılmalı Birim Kök Testi Sonuçları 
Test modeli olarak, sabitte ve trendde yapısal kırılmaya izin veren model seçilmiştir. Yapısal kırılma tarihleri test yöntemi tarafından belirlenmiş tarihlerdir. Carrion-i-Silvestre vd. (2009) testi beş adete kadar yapısal kırılmayı göz önünde bulundurabilmektedir. Hesaplanan test istatistikleri, boostrap kritik değerlerden büyük olduğu için, $\mathrm{H}_{0}$ hipotezi kabul edilmekte ve yapısal kırılmalar altında LnRDK serisinde birim kök olduğu, yani serinin durağan olmadığı anlaşılmaktadır. Birinci mertebe fark alınarak yapılan testte ise, hesaplanan test istatistiklerinin kritik değerlerden küçük olduğu görülmektedir. $\mathrm{Bu}$ durumda $\mathrm{H}_{0}$ hipotezi reddedilmekte ve serilerin durağan hale geldikleri ve I(1) sonucuna ulaşılmaktadır.

Yapısal kırılmayı dikkate alan ve almayan birim kök testi analizlerinde elde edilen sonuç satın alma gücü paritesi teorisinin Türkiye ekonomisi için geçerli olmadığını ortaya koymaktadır. Literatürde farklı sonuçlara rastlanmaktadır. Bunun nedenini verinin çalışma aralığg, kullanılan yöntem gibi unsurlar oluşturabilmektedir.

\section{SONUÇ}

SGP, ülkeler arasındaki fiyat farklılıklarını ortadan kaldırarak, ulusal para birimlerini birbirine dönüştüren bir orandır. Aynı zamanda ülkeler arası gelişmişlik düzeyi karşılaştırmalarının daha doğru ve güvenilir bir şekilde yapılmasına da olanak tanımaktadır. Ülkelerin mal ve hizmetler için fiyat seviyelerinin döviz kurlarını temsil ettiği düşüncesinden yola çıkarak, fiyat seviyeleri arasında ilişki kurmaya çalışır. SGP, iki ülkenin ulusal fiyat seviyeleri ortak para birimi cinsinden ifade edildiğinde, fiyat seviyeleri arasında uzun dönemli ilişkinin varlığını ileri sürmektedir.

Türkiye'de 2001 krizi sonrası döviz kuru politikası üzerinde köklü değişiklikler yapılmıştır. Kriz sonrası önceden benimsenen döviz kuru çapasından vazgeçilmiş ve döviz dalgalanmaya bırakılmıştır. Dalgalı kur politikası ile artık liberal politika da bir kademe daha ileriye gidilmiş ve farklı bir döviz kuru politikası benimsenmiştir. Liberalleşen dünyaya ayak uyduran Türkiye ekonomisi diş etkilere daha açık hale gelmiştir. Bu nedenle, analizde 2000 yılı başlangıç dönemi olarak ele alınmıştır.

Bu çalışmada, SGP geçerliliği, Türkiye için 2000:01-2014:12 dönemi aylık verileri kullanarak analiz edilmiş ve RDK serisinin durağanlığının incelenmesiyle test edilmiştir. Analizde öncelikle RDK serisinin durağanlığı, yapısal kırılmaları dikkate almayan genişletilmiş ADF ve PP birim kök testleri ve yapısal kırılmaları dikkate alarak analiz eden Carrion-i-Silvestre vd. (2009) testleriyle incelenmiştir. ADF ve PP test sonuçlarına RDK serisi birim kök içerdiği yani düzeyde durağan olmadığı tespit edilmiştir. Aynı şekilde, çoklu yapısal kırılmalı test Carrion-i-Silvestre vd. (2009) sonuçları da düzeyde durağanlığı reddetmiş, birinci mertebe fark sonucunda durağanlığı belirlemiştir. Böylece SGP'nin ele alınan dönemde geçerli olmadığı ortaya konulmuştur. Diğer bir ifadeyle, reel kurlar ortalamaya dönme eğiliminde değildir ve dolayısıyla SGP ele alınan dönem itibarıyla geçerli bulunmamıştır. Reel döviz kurlarındaki yapısal kırılmalara, risk algılamasının değişmesi sonucu oluşan ani sermaye hareketleri, finansal krizler ve bunun sonucunda değişen faiz oranları, döviz kuru sistemindeki değişiklikler, devalüasyon, enflasyonda beklenenin üzerinde gerçekleşen artışlar, spekülatif ataklar, merkez bankalarının döviz piyasasına müdahaleleri ve gümrük sistemindeki değişiklikler gibi etmenler neden olabilir. Özellikle gelişmekte olan ülkelerin çoğunda 
ekonomik ve finansal piyasalarında meydana gelen bir takım dalgalanmaların döviz kurunda önemli değişikliklere yol açtığı görülmektedir. 


\section{REFERENCES}

- ALBA, J. D. ve PARK, D. (2005). Non-Linear mean reversion of real exchange rates and purchasing power parity: Some evidence from Turkey. Applied Economics Letters, 12(11), 701-704.

- BAI, J. ve PERRON, P. (2003). Computation and analysis of multiple structural change models. Journal of Applied Econometrics. 18, 1-22.

- BOZOKLU, Ş. ve YILANCI V. (2010). Reel döviz kurlarının durağanlığı: E7 ülkeleri için ampirik bir inceleme. Maliye Dergisi, 158, 587-606.

- BREITUNG, J. ve CANDELON, B. (2005). Purchasing power parity during currency crises: A panel unit root test under structural breaks. Review of World Economics, 141(1), 124-140.

- CARRION-I-Silvestre, J. L., Kim, D. ve Perron, P. (2009). GLS-based unit root tests with multiple structural breaks under both the null and the alternative hypotheses, Econometric Theory, 25, 1754-1792.

- CERRATO, M. ve SARANTIS, N. (2007). A bootstrap panel unit root test under cross-sectional dependence, with an application to PPP. Computational Statistics and Data Analysis, 51(8), 4028-4037.

- CEYLAN R. ve ULUCAN H. (2014). Satın alma gücü paritesi hipotezinin OECD ülkeleri için test edilmesi. Sosyo-Ekonomi Dergisi, 2(1), 193-210.

- COAKLEY, J. ve FUERTES, A. M. (1997). New panel unit root tests of PPP, Economics Letter, 57(1), 17-22.

- ÇAĞLAYAN, E. ve SAK, N. (2009). OECD ülkelerinde satın alma gücü paritesi: Panel eşbütünleşme yaklaşımı. Marmara Üniversitesi İIBF Dergisi, 26(1), 483-500.

- DICKEY, D. ve FULLER, W. (1979). Distribution of the estimates for autoregressive time series with a unit root. Journal of the American Statistical Association, 74, 427431.

- ENDERS, W. (1989). Unit roots and the real exchange rate before World War I: The case of Britain and the USA. Journal of International Money and Finance, 8, 59-73.

- ERLAT, H. (2003). The nature of persistence in Turkish real exchange rates. Emerging Markets Finance and Trade, 39(2), 70-97.

- GANIEV, C. ve EMSEN, Ö. S. (2008). Kırgızistan'da döviz kurlarınınyönü: Satın alma gücü paritesi yaklaşımı. Kırgızistan-Türkiye Manas Üniversitesi Sosyal Bilimler Dergisi, 20, 95-113.

- GÜlOĞLU, B., İSPİR, S. ve OKAT, D. (2011). Testing the vallidity of quasi PPP hypothesis: Evidence from a recent panel unit root test with structural break. Applied Economics Letter, 18(18), 1817-1822.

- GÜNEY, P. Ö., TELATAR, E. ve HASANOV, M. (2012). Re-examining purchasing power parity for selected emerging markets and African countries. Applied Economics Letters, 19(2), 139-144.

- HOLMES, M. J., OTERO, J. ve PANAGIOTIDIS, T. (2012). PPP in OECD countries: An analysis of real exchange rate stationarity, cross-sectional dependency and structural breaks. Open Economies Review, 23(5), 767-783. 
- KAlYONCU, H. ve KALYONCU, K. (2008). Purchasing power parity in OECD countries: Evidence from panel unit root. Economic Modelling, 25(3), 440-445.

- KALYONCU, H., KULA, F. ve ASLAN, A. (2010). The validity of purchasing power parity hypothesis in Middle East and Northern African countries, Romanian Journal of Economic Forecasting, 4(13), 125-131.

- KRUGMAN, P. R. ve OBSTFELD, M. (2006). International economics: Theory and policy. 7.b., ABD: Addison Wesley.

- LAU, C. K. M. (2009). A more powerful panel unit root test with an application to PPP, Applied Economics Letters, 16(1), 75-80.

- O'CONNELL, P. G. J. (1998). The overvaluation of purchasing power parity. Journal of International Economics, 44(1), 1-19.

- PERRON, P. (1989). The great crash, the oil price shock, and the unit root hypothesis. Econometrica, 57(2), 1361-1401.

- SARNO, L. (2000). Real exchange rate behavior in high inflation countries: Empirical evidence from Turkey, 1980-1997. Applied Economics Letters, 7(5), 285-291.

- SARNO, L. ve VALENTE, G. (2006). Deviations from purchasing power parity under different exchange rate regimes: Do they revert and, if so, how? Journal of Banking and Finance, 30(11), 3147-3169.

- TELATAR, E. ve KAZDAĞLI, H. (1998). Re-Examine the long-run purchasing power parity hypothesis for a high inflation country: The case of Turkey 1980-93. Applied Economics Letters, 5(1), 51-53.

- TIRAŞOĞLU, B. Y. (2014). Yapısal kırılmalı birim kök testleri ile OECD ülkelerinde satın alma gücü paritesi geçerliliğinin testi. ÏU İktisat Fakültesi Ekonometri ve Istatistik Dergisi, 20, 68-87.

- YAZGAN, M. E. (2003). The purchasing power parity hypothesis for a high inflation Country: A re-examination of the case of Turkey. Applied Economics Letters,10(3), 143-147.

- YILDIRIM K., MERCAN M. ve KOSTAKOĞLU F.S. (2013). Satın alma gücü paritesinin geçerliliğinin test edilmesi: Zaman serisi ve panel veri analizi. Eskişehir Osmangazi Üniversitesi IIIBF Dergisi, 8(3), 75- 95.

- YILDIRIM, O. (2003). Kura dayalı istikrar politikası, teori ve ülke uygulamalart. Ankara: Hazine Müsteşarlığı.

- YILDIRIM, S. ve YILDIRIM, Z. (2012). Reel efektif döviz kuru üzerinde kırılmalı birim kök testleri ile Türkiye için satın alma gücü paritesi hipotezinin geçerliliğinin s1nanmas1. Marmara Üniversitesi IIBBF Dergisi, 33(2), 221-238. 